\title{
Chronic inhibition of cyclic GMP phosphodiesterase 5 A prevents and reverses endothelial dysfunction and oxidative stress associated with the metabolic syndrome
}

\author{
Behr-Roussel Delphine*1, Alexandra Oudot ${ }^{1}$, Stephanie Caisey ${ }^{1}$, Olivier Le \\ $\mathrm{Coz}^{1}$, Diane Gorny ${ }^{1}$, Jaques Bernabé ${ }^{1}$, Chris Wayman², Laurent Alexandre ${ }^{1}$ \\ and Francois Giuliano ${ }^{3}$
}

\author{
Address: ${ }^{1}$ Pelvipharm, Gif-sur-Yvette, France, ${ }^{2}$ Department of Sexual Health, Pfizer Global Research and Development, Sandwich, Kent, UK and \\ ${ }^{3}$ Department of Neurological Rehabilitation, AP-HP Raymond Poincaré hospital, Garches, France \\ Email: Behr-Roussel Delphine* - d.behr.roussel@pelvipharm.com \\ * Corresponding author
}

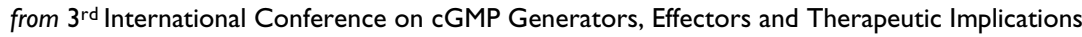

Dresden, Germany. 15-17 June 2007

Published: 25 July 2007

BMC Pharmacology 2007, 7(Suppl I):S28 doi:10.1 |86/I47I-22I0-7-SI-S28

This abstract is available from: http://www.biomedcentral.com/I47I-22 I0/7/SI/S28

C 2007 Delphine et al; licensee BioMed Central Ltd.

\section{Background}

Patients with metabolic syndrome exhibit generalized endothelial dysfunction with decreased NO production and increased vascular oxidative stress. We postulated that chronic treatment with sildenafil could upregulate the NOS/cGMP pathway and improve endothelial function in fructose-fed rats.

\section{Materials and methods}

Wistar rats $(\mathrm{n}=10-14$ per group) were fed a standard chow (CONT) or a $60 \%$ fructose $/ 5 \%$ fat ( $\%$ by weight)enriched diet for 8 weeks (FFR). From week 5 through 8 , sildenafil was administered twice a day (sc, $20 \mathrm{mg} / \mathrm{kg}$, FFR+SIL), thus reaching clinically relevant plasma concentrations circa $20 \mathrm{nM}$ unbound known to give efficacy in man (Pfizer Inc., data on file), then a 1-week wash-out period from sildenafil was observed. Isometric tension studies were performed on isolated aortic and superior mesenteric arterial (SMA) rings precontracted with noradrenaline to build concentration-response curves (CRC) to endothelium-dependent (ACh and A23187) and -independent (SNP) relaxants in presence of indomethacin. Urinary 8-isoprostanes (IPT) and plasma levels of IL- 6 and TNF- $\alpha$ were also evaluated.

\section{Results}

Relaxations to ACh were reduced in aortas of FFR $\left(10^{-5} \mathrm{M}\right.$ : $-102.6 \pm-2.4 \%$ vs $-89.2 \pm 4.7, \mathrm{p}<0.001$ ) while only slightly affected in SMA rings. Relaxations to A23187 were significantly reduced both in aortic and SMA rings of FFR. In aortas, sildenafil treatment restored normal endothelium-dependent relaxations to ACh $\left(10^{-5} \mathrm{M}\right.$ : $-104.2 \pm$ $3.0 \%, \mathrm{p}<0.001$ ) even after one week of wash-out from treatment. In SMA rings, a leftward shift of the CRC to ACh could be detected ( $\mathrm{pD} 2:-8.12 \pm 0.11$ vs $-8.60 \pm 0.08$, $\mathrm{p}<0.05$ ). Relaxations to A23187 were also restored by sildenafil in both aortic and SMA rings of FFR. Enhanced compensatory endothelium-independent relaxations to SNP in FFR were not modified by sildenafil treatment. Neither IL- 6 nor TNF- $\alpha$ were modified by the fructose or sildenafil treatment. Urinary IPT levels was normalized by the sildenafil treatment (FFR: $2.07 \pm 0.36$ vs CONT:0.95 \pm 0.14 vs FFR+SIL: $0.88 \pm 0.13 \mathrm{ng} / \mathrm{ml} / 24 \mathrm{~h}, \mathrm{p}<0.05)$.

\section{Conclusion}

Endothelial dysfunction and oxidative stress associated with the metabolic syndrome can be reversed in FFR by a chronic treatment with sildenafil, even 7 days after treatment has ceased. This sustained improvement in endothelial function suggests that chronic administration of 
sildenafil may lead to structural and molecular changes within the vascular wall that may be of benefit in vascular cardio-metabolic indications.

\section{Acknowledgements}

This study was supported by an independent investigator research grant from Pfizer.

Publish with Bio Med Central and every scientist can read your work free of charge

"BioMed Central will be the most significant development for disseminating the results of biomedical research in our lifetime. " Sir Paul Nurse, Cancer Research UK

Your research papers will be:

- available free of charge to the entire biomedical community

- peer reviewed and published immediately upon acceptance

- cited in PubMed and archived on PubMed Central

- yours - you keep the copyright 